\title{
A Case of Graves' Disease Complicated With Thyroid Storm and Acute Hepatic Failure
}

\author{
Akinori Watanabe ${ }^{\text {a, d }}$, Hisashi Hidaka ${ }^{\text {a }}$, Tsutomu Minamino ${ }^{\text {, }}$ Yoshiaki Tanaka ${ }^{a}$, Juichi Takada \\ Yusuke Okuwaki ${ }^{a}$, Takahide Nakazawa ${ }^{a}$, Akitaka Shibuya ${ }^{a}$, Kento Nakatani ${ }^{\text {b }}$, \\ Makoto Ohbu ${ }^{c}$, Wasaburo Koizumi ${ }^{\mathrm{a}}$
}

\begin{abstract}
A 44-year-old man was transferred to our hospital because of deterioration of liver function. He was diagnosed as having Graves' disease, congestive heart failure and cholestatic liver failure, and started treatment with oral iodine, thiamazole, diuretics and $\beta$-blockers. The patient's condition was complicated with thyroid storm and spontaneous bacterial peritonitis (SBP). But the treatment for Graves' disease and SBP quickly cured the thyroid storm. Along with the improvement of the hyperthyroidism, the liver function also improved rapidly. We experienced a case of liver dysfunction that was caused by not treating Graves' disease. The present case suggested the importance of including Graves' disease in the differential diagnoses in cases of liver dysfunction.
\end{abstract}

Keywords: Graves' disease; Liver dysfunction; Acute hepatic failure; Thyroid storm; Hyperthyroidism; Hyperbilirubinemia

\section{Introduction}

Complications of liver dysfunction associated with Graves' disease are relatively mild; therefore, critical problems do not usually occur in most cases. However, there have been a few reported cases of liver failure caused by hyperthyroidism, but its pathogenesis and mechanism remain unclear. We herein report a case of a man with Graves' disease complicated by acute hepatic failure and thyroid storm that was re-

Manuscript accepted for publication January 14, 2014

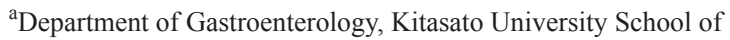
Medicine, 1-15-1 Kitasato, Minami, Sagamihara, Kanagawa, Japan

${ }^{\mathrm{b}}$ Department of Kitasato University Emergency Center, Sagamihara, Kanagawa, Japan

${ }^{c}$ Department of Pathology, Kitasato University East Hospital, 2-1-1

Asamizodai, Minami, Sagamihara, Kanagawa, Japan

${ }^{\mathrm{d}}$ Corresponding author: Akinori Watanabe, Department of

Gastroenterology, Kitasato University School of Medicine, 2-1-1

Asamizodai, Minami, Sagamihara, Kanagawa 252-0328, Japan.

Email: akinori@kitasato-u.ac.jp

doi: http://dx.doi.org/10.14740/jmc1647w solved successfully with treatment.

\section{Case Report}

A 44-year-old man was taken to a hospital where he presented with motor aphasia in March. He had a history of atrial fibrillation and hypertension that had been medicated with warfarin potassium and nifedipine for 1 year. He was diagnosed with cardiogenic cerebral infarction and admitted to that hospital. Prospectively, a blood test at the initial examination showed his total bilirubin was $3.9 \mathrm{mg} / \mathrm{dL}$, aspartate aminotransferase was $52 \mathrm{IU} / \mathrm{L}$ and alanine aminotransferase was $40 \mathrm{IU} / \mathrm{L}$. After treatment, he had no symptoms and started rehabilitation. Blood examination revealed his total bilirubin had deteriorated to $11.1 \mathrm{mg} / \mathrm{dL}$ on April 2. At that time, his aspartate aminotransferase was $55 \mathrm{IU} / \mathrm{L}$, and alanine aminotransferase was $45 \mathrm{IU} / \mathrm{L}$. He was diagnosed as having congestive liver for which treatment was started with furosemide; however, within 2 weeks, he had lost $10 \mathrm{~kg}$ from $76 \mathrm{~kg}$ body weight on admission. However, his serum bilirubin level was increasing, at which time, he was transferred to our hospital.

He was $164.5 \mathrm{~cm}$ tall and weighed $62.9 \mathrm{~kg}$ on admission. Although he had been obese since childhood, he had lost 40 $\mathrm{kg}$ (from $100 \mathrm{~kg}$ to $60 \mathrm{~kg}$ ) in the last 7 years from when he was 37 years old. His blood pressure was 130/74 $\mathrm{mmHg}$, heart rate $85 / \mathrm{min}$ with arrhythmia, with a body temperature of $37.3{ }^{\circ} \mathrm{C}$. His level of consciousness was alert, and flapping tremor was not observed. His conjunctiva showed jaundice. Exophthalmoses and goiter were not observed. Pulmonary and cardiac sounds were normal, abdomen was soft with no tenderness or striae cutis distensae (namely, stretch marks, due to the considerable weight loss from 37 years old). Both legs were edematous. Blood examination revealed hyperthyroidism, a low level of thyroid-stimulating hormone, thrombocytopenia, prolonged prothrombin time, low albumin and congestive hepatopathy. Based on these results, the patient was diagnosed as having Graves' disease (Table 1). Hepatitis antibodies were not detected, but the B-type natriuretic peptide level was high. Chest X-ray showed cardiac dilation of which the cardiothoracic ratio was $54 \%$. Echocardiography 
Table 1. Laboratory Findings on Admission

\begin{tabular}{|c|c|}
\hline Hematology & Glu $121 \mathrm{mg} / \mathrm{dL}$ \\
\hline WBC $7700 / \mu \mathrm{L}$ & T-Chol 29 mg/dL \\
\hline $\mathrm{RBC} 376 \times 10^{4} / \mu \mathrm{L}$ & TG $49 \mathrm{mg} / \mathrm{dL}$ \\
\hline $\mathrm{Hb} 11.8 \mathrm{~g} / \mathrm{dL}$ & $\mathrm{Na} 138 \mathrm{mEq} / \mathrm{L}$ \\
\hline Ht $33.7 \%$ & $\mathrm{~K} 2.6 \mathrm{mEq} / \mathrm{L}$ \\
\hline Plt $9.4 \times 10^{4} / \mu \mathrm{L}$ & $\mathrm{Cl} 94 \mathrm{mEq} / \mathrm{L}$ \\
\hline Coagulation and fibrinolysis tests & $\mathrm{Ca} 8.1 \mathrm{mg} / \mathrm{dL}$ \\
\hline $\mathrm{PT}<5.0 \%$ & $\mathrm{NH} 330 \mu \mathrm{g} / \mathrm{dL}$ \\
\hline APTT $82.9 \mathrm{sec}$ & CRP $2.11 \mathrm{mg} / \mathrm{dL}$ \\
\hline Fibrinogen $103.1 \mathrm{mg} / \mathrm{dL}$ & TBA $87.1 \mu \mathrm{mol} / \mathrm{L}$ \\
\hline $\mathrm{FDP}<2.5 \mu \mathrm{g} / \mathrm{dL}$ & ANA 1:40 \\
\hline AT-III 33.8\% & $\operatorname{AMA}(\mathrm{M} 2)<5 \mathrm{U} / \mathrm{mL}$ \\
\hline Serum chemistry & $\operatorname{IgG} 2600 \mathrm{mg} / \mathrm{dL}$ \\
\hline $\mathrm{TP} 6.5 \mathrm{~g} / \mathrm{dL}$ & HBsAg (-) \\
\hline Alb $2.3 \mathrm{~g} / \mathrm{dL}$ & $\operatorname{HCVAb}(-)$ \\
\hline TBIL $27.5 \mathrm{mg} / \mathrm{dL}$ & EB VCA-G $(+)$ \\
\hline DBIL $24.8 \mathrm{mg} / \mathrm{dL}$ & EB VCA-M (-) \\
\hline BUN $25.4 \mathrm{mg} / \mathrm{dL}$ & $\operatorname{IgM}-\mathrm{HBcAb}(-)$ \\
\hline $\mathrm{Cr} 1.09 \mathrm{mg} / \mathrm{dL}$ & EBNAIgG $(+)$ \\
\hline UA $5.1 \mathrm{mg} / \mathrm{dL}$ & CMV-IgG $(+)$ \\
\hline AST $49 \mathrm{U} / \mathrm{L}$ & CMV-IgM (-) \\
\hline ALT $42 \mathrm{U} / \mathrm{L}$ & BNP $651 \mathrm{pg} / \mathrm{mL}$ \\
\hline ALP $522 \mathrm{U} / \mathrm{L}$ & $\mathrm{TSH}<0.003 \mu \mathrm{IU} / \mathrm{mL}$ \\
\hline$\gamma$-GTP $25 \mathrm{U} / \mathrm{L}$ & FT3 $15 \mathrm{pg} / \mathrm{dL}$ \\
\hline Ch-E $48 \mathrm{U} / \mathrm{L}$ & FT4 4.73 ng/dL \\
\hline LDH $283 \mathrm{U} / \mathrm{L}$ & TRAb $80.3 \%$ \\
\hline CPK $67 \mathrm{U} / \mathrm{L}$ & \\
\hline
\end{tabular}

WBC: white blood cells; RBC: red blood cells; Ht: hematocrit; PIt: platelet; PT: prothrombin time; APTT: activated partial thromboplastin time; FDP: fibrin-fibrinogen degradation products; AT-III: antithronbin-III; TP: total protein; Alb: albumin; TBIL: total bilirubin; DBIL: direct bilirubin; BUN: blood urea nitrogen; Cr: creatinine; UA: uric acid; AST: aspartate aminotransferase; ALT: alanine aminotaransferase; Y-GTP: gamma glutamyltranspeptidase; Ch-E: cholinesterase; LDH: lactate dehydrogenase; CPK: creatine phosphokinase; Glu: glucose; T-Chol: total cholesterol; TG: trigricelide; NH3: ammonia; CRP: C-reactive protein; TBA: total bile acid; ANA: anti-nuclear antibody; AMA: anti-mitochondrial M2 antibody; IgG: immunoglobulin G; HBsAg: hepatitis B surface antigen; HCVAb: hepatitis C virus antibody; EB VCA-G: Epstein-Barr virus capsid antibody IgG; EB VCA-M: EB virus capsid antibody IgM; IgM-HBcAb: hepatitis B core antibody IgM; EBNAlgG: EB virus determined nuclear antigen IgG; CMV-lgG: cytomegalovirus antigen IgG; BNP: brain natriuretic peptide; TSH: thyroid stimulating hormone; FT3: free triiodothyronine; FT4: free thyroxine; TRAb: thyrotropin receptor antibody.

revealed the ejection fraction was $65 \%$, with no asynergy, and no dilation of the right heart. Abdominal ultrasonography showed that the inferior vena cava and the hepatic vain were dilated, the liver margin dull, the right lobe atrophic, and the intrahepatic bile ducts were not dilated (Fig. 1). Examination of the thyroid using color-coded duplex ultrasonography showed an enlarged thyroid and active blood flow, which indicated hyperthyroidism (Fig. 2). Computed tomog- raphy showed atrophy of the right liver lobe, splenomegaly and ascites in the rectovesical excavation. There was an atrophic change in only the right hepatic lobe but no atrophy or hypertrophy in the left lobe.

The patient was diagnosed as having congestive hepatopathy, Graves' disease and congestive heart failure (CHF, New York Heart Association Class I) with atrial fibrillation. We started oral ursodeoxycholic acid and intravenous 


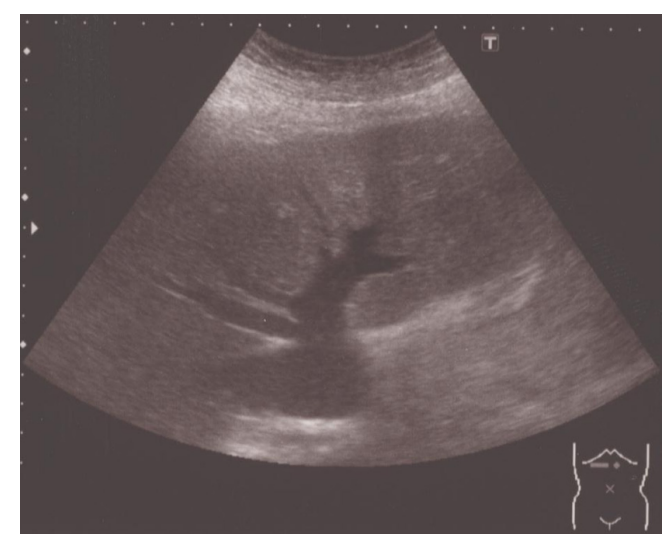

Figure 1. Abdominal ultrasonography showed dilated inferior vena cava and hepatic vein, liver margin was dull, right lobe was atrophic and intrahepatic bile ducts were not dilated.

administration of vitamin $\mathrm{K}$ for the liver dysfunction, oral thiamazole (20 mg/day) and iodine (100 mg/day) for Graves' disease, and $\beta$-blocker and intravenous administration of furosemide for the CHF. However, 6 days after admission, the patient had a fever of $39.8^{\circ} \mathrm{C}, 130 / \mathrm{min}$ tachycardia and diarrhea. And 3 days later, a flapping tremor appeared, and the patient showed signs of disorientation (Japan Coma Scale I-3, Glasgow Coma Scale 14, New York Heart Association Class III). In addition, his plasma ammonia level was $61 \mu \mathrm{g} /$ $\mathrm{dL}$. Therefore, he was diagnosed as having thyroid storm [1], hepatic encephalopathy (grade II according to the West Haven Criteria [2]), spontaneous bacterial peritonitis (SBP) and septic shock by various examinations including abdominal paracentesis. Then we administered the antibiotic therapy of ceftriaxone, immunoglobulin and catecholamine, after which the patient's symptoms immediately improved.

With this treatment regimen, the liver dysfunction gradually improved evidenced by the decrease of thyroid hormone (Fig. 3). However, 58 days after admission, a blood examination showed neutropenia $(32 / \mu \mathrm{L})$ caused by thiamazole; therefore, we stopped the drug and started the antibiotic therapy of cefepime and filgrastim. Without a complicating severe infection, the neutrocytes returned to a normal level within 2 weeks. However, thyroid hormone increased even higher during the discontinuance of thiamazole; therefore, we performed isotope therapy with $6 \mathrm{mCi}$ radioiodine. The thyroid hormone level gradually decreased. During the hospitalization, the atrial fibrillation returned to a normal sinus rhythm, and the CHF resolved, so we stopped the $\beta$-blocker and furosemide.

After about 4 months, the patient was discharged without any symptoms and did not require any drugs. At that time, the platelet level returned to normal $\left(15.5 \times 10^{4} / \mu \mathrm{L}\right)$. We performed a liver biopsy to identify the cause of the liver dysfunction as a follow-up examination 7 months after the admission, which revealed confluent necrosis and bile

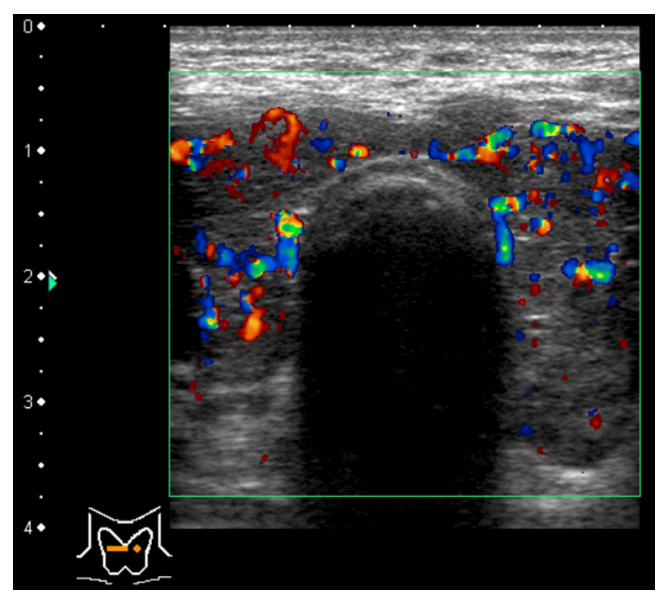

Figure 2. Thyroid color duplex ultrasonography showed enlarged thyroid and active blood flow indicating hyperthyroidism.

thrombus from the periportal to the intermediate zone. However, no pathological features of autoimmune hepatitis or congestive liver were detected.

\section{Discussion}

The complication of liver dysfunction associated with Graves' disease is usually mild in most cases and rarely develops into liver failure $[3,4]$. There were eight previous reports of Graves' disease complicated with liver failure, and the chief complaints in those cases were caused by Graves' disease. Therefore, this is a rare case in that the liver dysfunction and jaundice primarily appeared before the complication of thyroid storm (Table 2) [5-11].

These clinical courses suggest that the liver dysfunction was mainly caused by Graves' disease. The scientific literature describes some cases of severe cholestasis linked with hyperthyroidism [5-11]. These cases are often complicated with CHF. On the other hand, Hull et al [11] reported two cases of marked cholestatic jaundice as a complication of hyperthyroidism in the absence of CHF. They have considered the following hypotheses, hypo-oxygenic state and thyroid hormone's direct toxic effect. However, there is no firm evidence to support either. In these cases, severe cholestasis improved in parallel with the improvement of hyperthyroidism during therapy, and the case in the present study's clinical course is similar to these. In addition, other liver diseases, for example, viral hepatitis, primary biliary cirrhosis and autoimmune hepatitis, can be ruled out by the lack of specific serum markers or pathological findings. Moreover, druginduced liver injury was also a low probability as evidenced by the diagnostic score referenced by the CIOMS/RUCAM scale in the Digestive Disease Week Japan (DDW-J) 2004. There is no evidence of constitutional jaundice in his past 


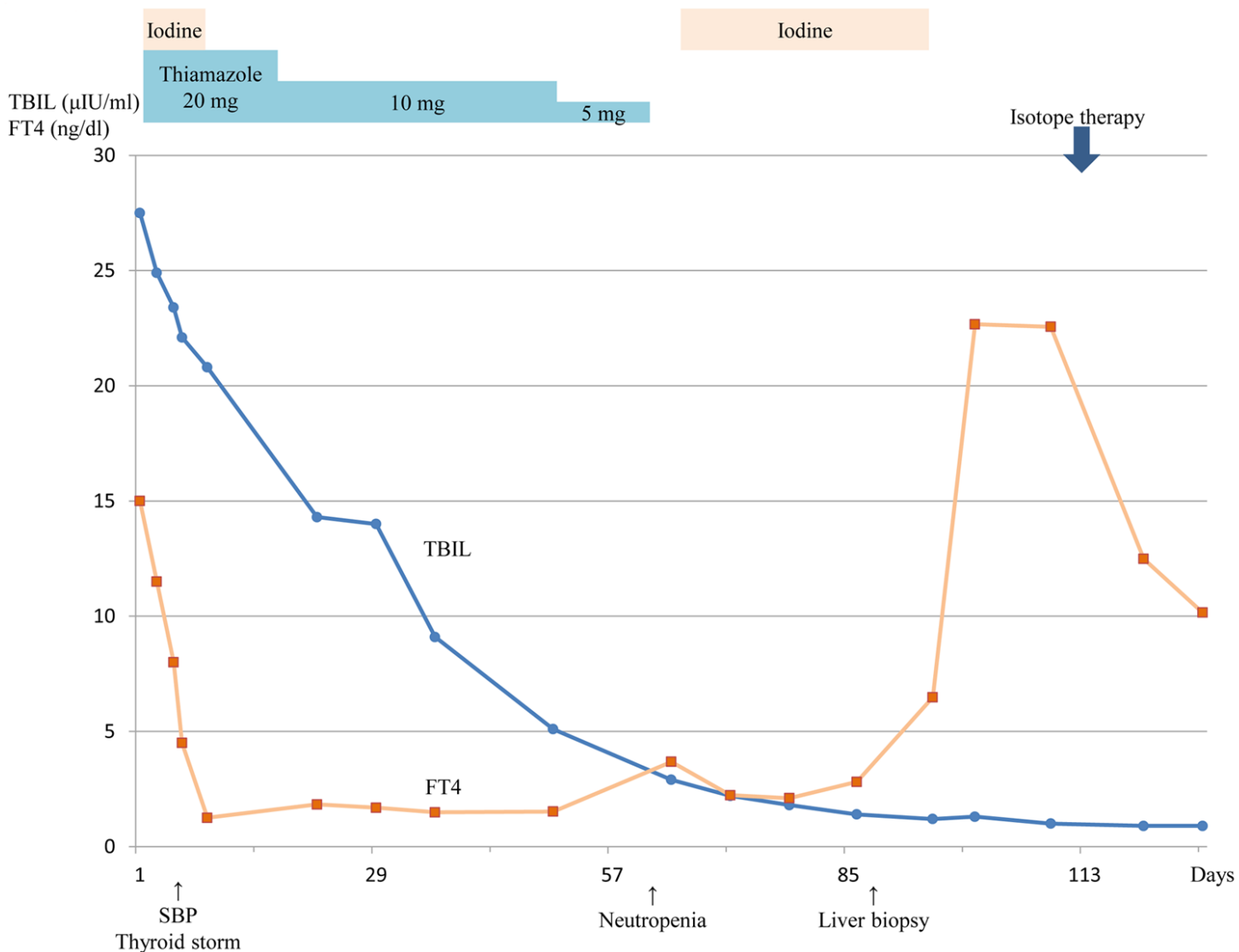

Figure 3. Clinical course after admission.

history or family history. And serum bilirubin improved to within a normal level, so he was discharged. However, it is also necessary to consider other multiple factors involved in this particular case of liver dysfunction.

There are five possibilities for mechanisms of inducing liver dysfunction with hyperthyroidism: malnutrition, CHF, infection, the direct toxic effect of thyroid hormone and hepatic anoxia $[12,13]$. Firstly, regarding malnutrition, the blood test in the previous hospital showed albumin at $3.1 \mathrm{~g} /$ $\mathrm{dL}$ and total cholesterol at $107 \mathrm{mg} / \mathrm{dL}$. While the blood test in our hospital also showed low albumin level, triglyceride and total cholesterol. These demonstrate chronic malnutrition, but the mechanisms remain unclear $[12,14-16]$. Secondly, CHF had already presented on admission at the previous hospital. Although medications were started, the liver dysfunction did not resolve soon. And if CHF had caused the severe liver dysfunction, the pathological findings would have shown fibrosis around the central vein. Therefore, CHF was most likely not the only factor causing the liver dysfunction. Thirdly, the clinical course in the present case was not a continuous infectious episode. Even though the patient's condition was complicated with SBP, the liver dysfunction was not exacerbated. Therefore, infection was a possible contributing factor of the liver dysfunction. Fourthly, it is also likely that hyperthyroidism had continued since the patient began losing weight from when he was 37 years old, which continued for 7 years. Long-term exposure to hyperthyroidism might be one of the causes of the liver dysfunction. Moreover, re-elevation of thyroid hormone after stopping the thiamazole did not exacerbate the liver dysfunction. Therefore, this clinical course shows that long-term exposure to hyperthyroidism and other multiple factors are necessary for liver dysfunction to the present. Finally, hyperthyroidism generally increases oxygen demand in the liver and leads to a relatively hypo-oxygenated state. If the liver dysfunction was caused only by a state of hypo-oxygenation, pathological findings commonly show liver fibrosis around the central vein. But the pathological findings were quite different in the present case. However, it cannot be ruled out that a relatively long-term state of hypo-oxygenation might have been involved. From the above description, any one of these alone would not necessarily be enough to cause liver dysfunction; therefore, we thought there were multiple factors that caused the liver dysfunction in this case.

We considered that this patient had chronic liver dysfunction, as in Graves' disease, because blood examinations 


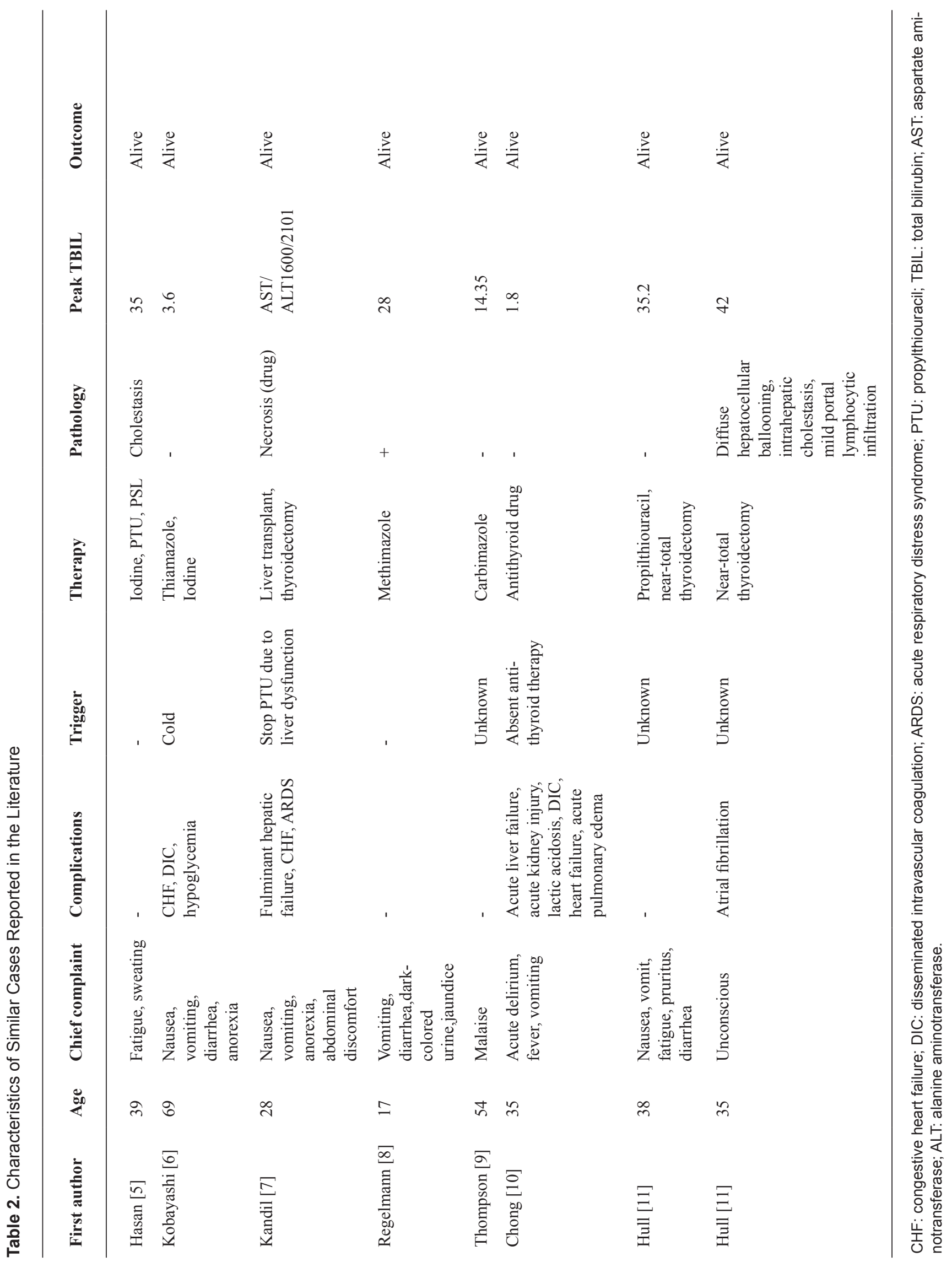


in the previous hospital showed mildly elevated transaminase and bilirubin. Furthermore, it is possible for chronic liver dysfunction to make the right liver lobe atrophic, and pathological findings showed confluent necrosis. However, Dooner et al [17] reported there was no specific hallmark pathological finding in the livers of patients with hyperthyroidism. Moreover, the degree of liver dysfunction, such as the levels of bilirubin or transaminase, does not correlate with pathological findings. Therefore, we considered that multiple factors caused by hyperthyroidism and chronic liver dysfunction made the pathological findings non-specific.

The severe clinical course in the present case might have been avoided if the patient's thyroid hormone had been checked earlier. The first time it had been checked was when the patient suddenly started losing weight when he was 37 years old, the second time was when the medications for hypertension and atrial fibrillation were started and the third time was when he had a stroke. These events prove that it is important to diagnosis hyperthyroidism as earlier as possible because thyroid storm is a life-threatening critical state.

In conclusion, we experienced a case of Graves' disease that had not been treated for a long term and was complicated with thyroid storm and acute hepatic failure; however, the patient recovered with antithyroid therapy. The pathogenesis and mechanism of the relation between hyperthyroidism and liver dysfunction remain unclear. However, these findings suggest that it is important to consider hyperthyroidism in the differential diagnosis in cases of liver dysfunction.

\section{Acknowledgement}

The authors thank Shoma Chida and Yuji Kamata, Department of Endocrinology, Diabetes and Metabolism, Kitasato University School of Medicine, Sagamihara, Kanagawa, Japan, for their medical assistance. We also thank Robert E. Brandt (Founder, CEO, and CME, of MedEd Japan) for editing the manuscript.

\section{Conflict of Interest}

The authors state that they have no conflict of interest.

\section{References}

1. Akamizu T, Satoh T, Isozaki O, Suzuki A, Wakino S, Iburi T, Tsuboi K, et al. Diagnostic criteria, clinical features, and incidence of thyroid storm based on nationwide surveys. Thyroid. 2012;22(7):661-679.

2. Ferenci P, Lockwood A, Mullen K, Tarter R, Weissenborn K, Blei AT. Hepatic encephalopathy--definition, nomenclature, diagnosis, and quantification: final re- port of the working party at the 11th World Congresses of Gastroenterology, Vienna, 1998. Hepatology. 2002;35(3):716-721.

3. Biscoveanu M, Hasinski S. Abnormal results of liver function tests in patients with Graves' disease. Endocr Pract. 2000;6(5):367-369.

4. Fong TL, McHutchison JG, Reynolds TB. Hyperthyroidism and hepatic dysfunction. A case series analysis. J Clin Gastroenterol. 1992;14(3):240-244.

5. Hasan MK, Tierney WM, Baker MZ. Severe cholestatic jaundice in hyperthyroidism after treatment with 131-iodine. Am J Med Sci. 2004;328(6):348-350.

6. Kobayashi C, Sasaki H, Kosuge K, Miyakita Y, Hayakawa M, Suzuki A, Abe E, et al. Severe starvation hypoglycemia and congestive heart failure induced by thyroid crisis, with accidentally induced severe liver dysfunction and disseminated intravascular coagulation. Intern Med. 2005;44(3):234-239.

7. Kandil E, Khalek MA, Thethi T, Abd Elmageed Z, Khan A, Jaffe BM. Thyroid storm in a patient with fulminant hepatic failure. Laryngoscope. 2011;121(1):164-166.

8. Regelmann MO, Miloh T, Arnon R, Morotti R, Kerkar $\mathrm{N}$, Rapaport R. Graves' disease presenting with severe cholestasis. Thyroid. 2012;22(4):437-439.

9. Thompson NP, Leader S, Jamieson CP, Burnham WR, Burroughs AK. Reversible jaundice in primary biliary cirrhosis due to hyperthyroidism. Gastroenterology. 1994;106(5):1342-1343.

10. Chong HW, See KC, Phua J. Thyroid storm with multiorgan failure. Thyroid. 2010;20(3):333-336.

11. Hull K, Horenstein R, Naglieri R, Munir K, Ghany M, Celi FS. Two cases of thyroid storm-associated cholestatic jaundice. Endocr Pract. 2007;13(5):476-480.

12. Ashkar FS, Miller R, Smoak WM, 3rd, Gilson AJ. Liver disease in hyperthyroidism. South Med J. 1971;64(4):462-465.

13. Hirakawa A, Matsuo N, Shinya H, Kitazawa Y, Murakami N, Tanaka T. The effect of plasma exchange for a thyrotoxic crisis patient. J Jpn Soc Emerg Med. 2001;4:424428. (in Japanese).

14. Minakawa M, Katayama S. [Glycose and lipid metabolic disorder in thyroid dysfunction]. Sogo Rinsho. 2009;58:1583-1586. (in Japanese).

15. Hoogerbrugge N, Jansen H, Staels B, Kloet LT, Birkenhager JC. Growth hormone normalizes low-density lipoprotein receptor gene expression in hypothyroid rats. Metabolism. 1996;45(6):680-685.

16. Thompson GR, Soutar AK, Spengel FA, Jadhav A, Gavigan SJ, Myant NB. Defects of receptor-mediated low density lipoprotein catabolism in homozygous familial hypercholesterolemia and hypothyroidism in vivo. Proc Natl Acad Sci U S A. 1981;78(4):2591-2595.

17. Dooner HP, Parada J, Aliage C, Hoyl C. The liver in thyrotoxicosis. Arch Intern Med. 1967;120(1):25-32. 